\title{
Retrosigmoid Approach for Vestibular Schwannoma
}

\author{
Mohammed Aref $^{1}$ Katherine Kunigelis ${ }^{1} \quad$ Stephen P. Cass $^{2} \quad$ A. Samy Youssef ${ }^{1}$ \\ ${ }^{1}$ Department of Neurosurgery, University of Colorado, Aurora, \\ Colorado, United States \\ 2 Department of Otolaryngology, University of Colorado Hospital, \\ Aurora, Colorado, United States

\begin{abstract}
Address for correspondence A. Samy Youssef, MD, PhD, Department of Neurosurgery, University of Colorado, 12631 East 17th Street, Mail Stop C307, Aurora, CO 80045, United States (e-mail: samy.youssef@ucdenver.edu).
\end{abstract}

J Neurol Surg B 2019;80(suppl S3):S271.

\begin{abstract}
Keywords

- vestibular schwannoma

- cerebellopontine angle

- hearing preservation

- retrosigmoid

Vestibular schwannoma is a benign tumor that affects $3 \%$ of the population, but accounts for $85 \%$ of tumors occurring at the cerebellopontine angle (CPA). In this case, we present a 48-year-old female with history of cholesteatoma on the right and chronic suppurative otitis media on the left who presented with an 18 month history of bilateral hearing loss, worse on the right. Investigations revealed a right sided vestibular schwannoma measuring $1.6 \mathrm{~cm}$ in diameter. Audiogram revealed an AAO-HNS (American Academy of Otolaryngology-Head and Neck Surgery) class $C$ hearing on the right and class $B$ on the left. There are several management options for this size of vestibular schwannoma including observation and radiosurgery. However, preserving cochlear nerve function remains a challenging enterprise. Furthermore, the ideal management that confers the highest chance of hearing preservation remains heavily debated. Given the patient's young age, the goal of hearing preservation and the tumor size/extension into the CPA, surgery was decided through a right retrosigmoid transmeatal approach for tumor resection with intraoperative brain auditory evoked responses monitoring. For hearing preservation, we emphasize few important dissection techniques: tumor debulking from the top first to avoid early manipulation of the cochlear nerve at the bottom of the tumor, sharp dissection from medial to lateral off the vestibular nerve which is kept intact as a tension band to minimize cochlear nerve manipulations, and limit the drilling of the posterolateral wall of the internal auditory canal (IAC) medial to the labyrinth and endolymphatic apparatus. Postoperatively, the patient was discharged home within 2 days, with imaging showing a gross total resection. Follow-up audiogram shows unchanged pure tone thresholds.

The link to the Video can be found at: https://youtu.be/Z5ftkpJN5k8.
\end{abstract}

Conflict of Interest

None.

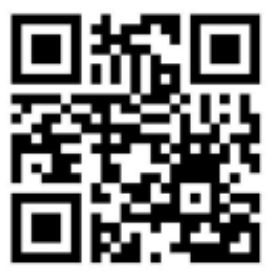

www.thieme.com/skullbasevideos

www.thieme.com/jnlsbvideos

received

April 28, 2018

accepted after revision

August 18, 2018

published online

November 26, 2018
DOI https://doi.org/

10.1055/s-0038-1673703. ISSN 2193-6331.
๑) 2019 Georg Thieme Verlag KG
Stuttgart · New York

License terms

(c) $(1) \$$ 